\title{
Bioprotective Efficacy of Erucin Against 7,12-Dimethylbenz(a)Anthracene-Induced Microstructural Changes in Male Wistar Rats
}

\author{
Rahul MANNAN', Rohit ARORA², Sakshi BHUSHAN³, Sonam SHARMA", Tejinder BHASIN', Saroj ARORA ${ }^{2}$ \\ 'Department of Pathology, Sri Guru Ram Das Institute of Medical Sciences and Research, AMRITSAR, INDIA, '2Department of Biochemistry, Sri Guru Ram Das \\ Institute of Medical Sciences and Research, AMRITSAR, INDIA, ${ }^{3}$ Department of Botanical and Environmental Sciences, Guru Nanak Dev University, AMRITSAR, \\ INDIA, ${ }^{4}$ Department of Pathology, Vardhman Mahavir Medical College and Safdarjung Hospital, NEW DELHI, INDIA
}

\begin{abstract}
Objective: Environmental pollutants are responsible for inducing a number of biochemical and physical changes in the various organs of an organism. The most potent pollutants is 7,12-dimethylbenz( $\alpha$ )anthracene (DMBA) (a genotoxic carcinogen), a polyaromatic hydrocarbon. It is known to induce a number of genetic changes including the formation of DNA adducts. These genotypic changes in turn are responsible for inducing microstructural changes in the vital organs viz. kidneys, stomach and lungs of an organism. These changes in turn cause biochemical alterations in an animal and hence alter the normal functioning. Synthetic drugs provide a sigh of relief but a large number of side effects in addition to the growing resistance has made it necessary to find an efficient alternative. Plant secondary metabolites, especially glucosinolate hydrolytic products, are known for their high bioprotective activity. The current study was therefore designed to analyze the bioprotective role of erucin against DMBA-induced microstructural changes in kidneys, lungs and stomach of male Wistar rats using histological analysis.
\end{abstract}

Material and Method: The bioprotective efficacy of erucin was evaluated in male Wistar rats against DMBA induced microstructural changes. The rats were divided into five groups where group I was untreated control, group II was DMBA treated and group III-V were treatment (DMBA + erucin) groups.

Results: Erucin was able to protect the rats against DMBA-induced histopathological changes in the lungs and stomach. No changes were observed in kidney following treatment with DMBA or erucin.

Conclusion: Erucin has bioprotective activity against genotoxic carcinogen.

Key Words: Isothiocyanate, Erucin, Polyaromatic hydrocarbons, DMBA, Histological analysis

\section{INTRODUCTION}

Environmental pollutants have always been known to induce various physiological and biochemical alterations in the living system (1). Among the various pollutants, 7,12-dimethylbenz( $\alpha$ )anthracene(DMBA) is the most potent mutagen released due to incomplete combustion (2). It has been known to induce microstructural changes (histopathological) in the liver tissue of male Wistar rats (3). These changes in turn are responsible for inducing biochemical changes in the animals and thus lead to the onset of various damaging effects. A number of drugs are available for countering these environmental pollutants but these often accompanied by serious side effects $(4,5)$. In addition, they mostly have limited efficacy and are prone to resistance development after a certain time period. These limitations of the synthetic drugs demand the use of natural plant products with diverse biological activities. Plant

(Turk Patoloji Derg 2017, 33:150-156)

Received : 09.09.2016 Accepted : 17.10.2016 secondary metabolites such as alkaloids, phenols, flavonoids and glucosinolates have shown immense biological activity and are often used as an antioxidant, antitumor, anticancer, bioherbicide and insecticide agents $(6,7)$. Among these, glucosinolates (GSLs) and especially their hydrolytic products have comparatively higher bioactivity with limited side effects (8). The current study was therefore designed to evaluate the protective activity of a glucosinolate hydrolytic product (GHP), erucin (4-methylthiobutyl isothiocyanate), against the microstructural changes induced by DMBA in the extrahepatic organs (lungs, stomach and kidneys) of male Wistar rats using histopathological analysis.

\section{MATERIAL and METHODS}

\section{Animals and Treatment}

Male albino rats of Wistar strains aged 40-80 days and weighing $0.15-0.30 \mathrm{~kg}$ were chosen for the current study. The rats were kept in polypropylene cages with paddy husk

Correspondence: Rohit ARORA

Sri Guru Ram Das Institute of Medical Sciences and Research,

Department of Biochemistry, AMRITSAR, INDIA

E-mail: rtarora23@gmail.com Phone: +9876010933 
bedding and maintained at a temperature of $25 \pm 2{ }^{\circ} \mathrm{C}$ and a $12 \mathrm{~h}$ light: $12 \mathrm{~h}$ dark condition in the animal house of Guru Nanak Dev University, Amritsar. They were allowed water and pellet diets at ad libitum. The study was approved by the animal ethical committee of GNDU, Amritsar with the file number 226/CPCSEA. The animal experimental analysis was done using the guidelines given by Committee for the Purpose of Control and Supervision of Experiments on Animals (CPCSE), Ministry of Environment and Forests, Government of India. The rats were divided in five groups and each group had a total of six rats. The first group was a negative control receiving corn oil (vehicle). The second group received DMBA $(20 \mathrm{mg} / \mathrm{kg} \mathrm{bw})$, and the third to fifth groups received DMBA + erucin $(20,35$ and $50 \mathrm{mg} / \mathrm{kg} \mathrm{bw}$ ). All the doses were given for five days through intraperitoneal injection and the experiment was terminated on the sixth day. The animals were sacrificed using cervical dislocation and their liver was removed under sterile conditions. The test compound erucin was isolated and characterized as per the earlier given method $(3,9)$.

\section{Histological Analysis}

The rats were euthanized and their lungs, stomach and kidneys were removed under sterile conditions and transported in $10 \%$ formalin to the histopathological unit. The organs were individually inspected and sections were taken from the representative areas. The sections were processed as per the standardized protocol and were embedded in paraffin blocks. Two to three micron sections were cut and then stained using haematoxylin and eosin. The slides thus prepared were segregated according to the specific organ system and then labeled in a blinded way to prevent any biasing. The slides themselves were observed on light microscope and scored by two histopathologists in a blinded manner. The observations were noted after a mutual consensus was reached by both the histopathologists. The scoring systems were designed before the start of the study. For the kidney, the European Vasculitis Study Group (EUVAS) classification system was chosen for characterisation of injury patterns. For gastric biopsies, the Baylor modification of "The Sydney System" for gastropathies was employed whereas for the lung, a novel injury score pattern was developed.

\section{RESULTS}

The histological studies were conducted in the three extrahepatic organs viz. lung, stomach and kidney and the results were presented as per the observed damage/ protection.

\section{Kidney}

Extensive study revealed the absence of any damage of either DMBA or erucin on the kidney of male Wistar rats (Figure 1A-C). A normal kidney tissue with intact structural characteristics was observed. No microstructural changes were observed following the treatment. The study therefore indicates absence of any role of the kidney in obviating DMBA induced damage. The mutagen was not able to cause any deleterious change in the structure and hence a normal physiological role of the organ was maintained, as observed by histological studies.

\section{Stomach}

The changes noted in the gastric biopsies were graded and scored according to the four main parameters: types of damage viz. chronic inflammation, activity, atrophy and intestinal metaplasia. These changes were further subdivided as no change, mild change, moderate and

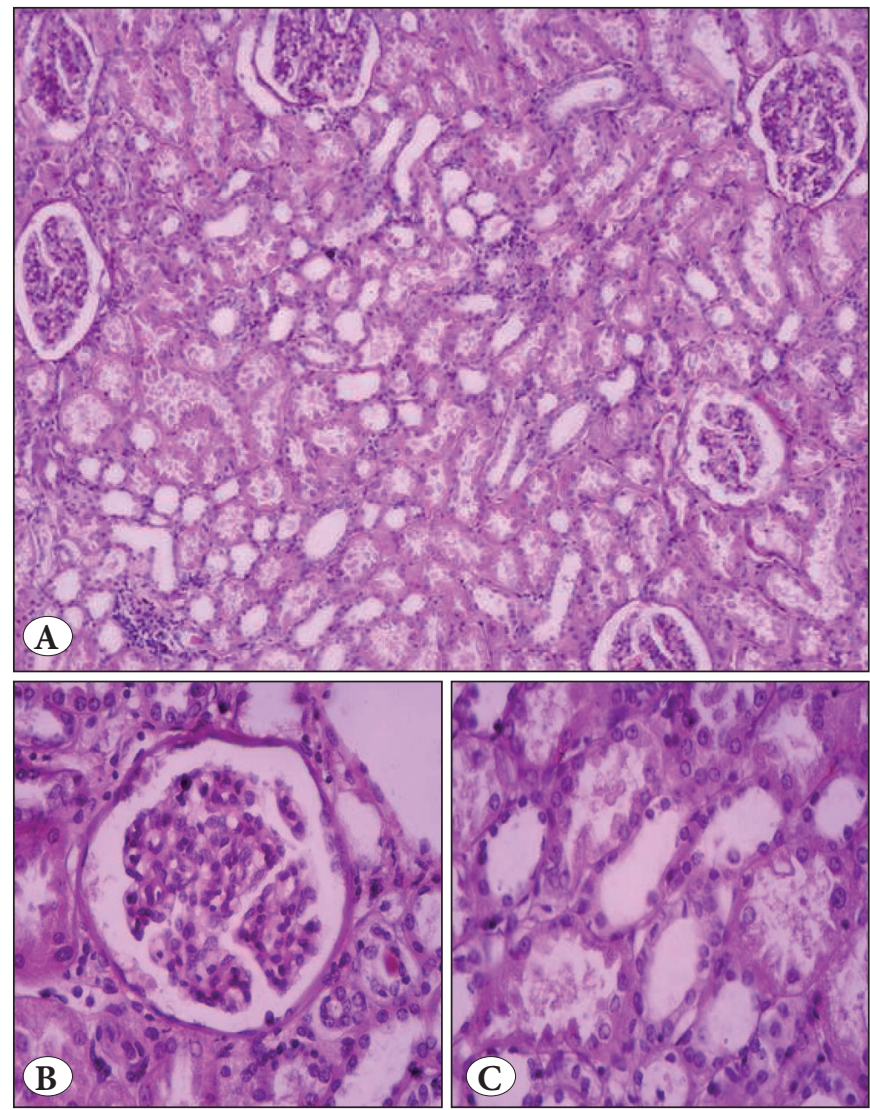

Figure 1: Figure representing normal kidney histopathology following the treatment with DMBA alone and in combination with erucin. A) Unremarkable renal parenchyma showing glomerulus, tubules, blood vessels and interstitium (H\&E; x100). B) Normal glomerulus with thin walled capillaries and surrounding normal tubules (H\&E; $\mathrm{x} 400)$. C) Unremarkable proximal and distal convoluted tubules (H\&Ex; x100). 
severe change. The scoring was then done as per the damage observed and cumulative score was considered as the total damage incurred in the organ of the animal following the treatment. The current study showed that the highest damage was in the stomach of DMBA-treated rats with a cumulative score of 8 out of 12 . Moderate chronic inflammation, activity, atrophy and intestinal metaplasia was seen in this treatment group. The untreated control group had mild chronic inflammation and a damage score of $1 / 12$ was recorded. In contrast, the treatment (DMBA + erucin) groups showed a dose-dependent result. The highest damage was in the DMBA $+20 \mathrm{mg} / \mathrm{kg}$ bw erucin group, with a score of $5 / 12$. This damage was further reduced to $3 / 12$ and $1 / 12$ in the group treated with 35 and $50 \mathrm{mg} / \mathrm{kg}$ bw erucin, respectively (Table I, Figure 2A-D).
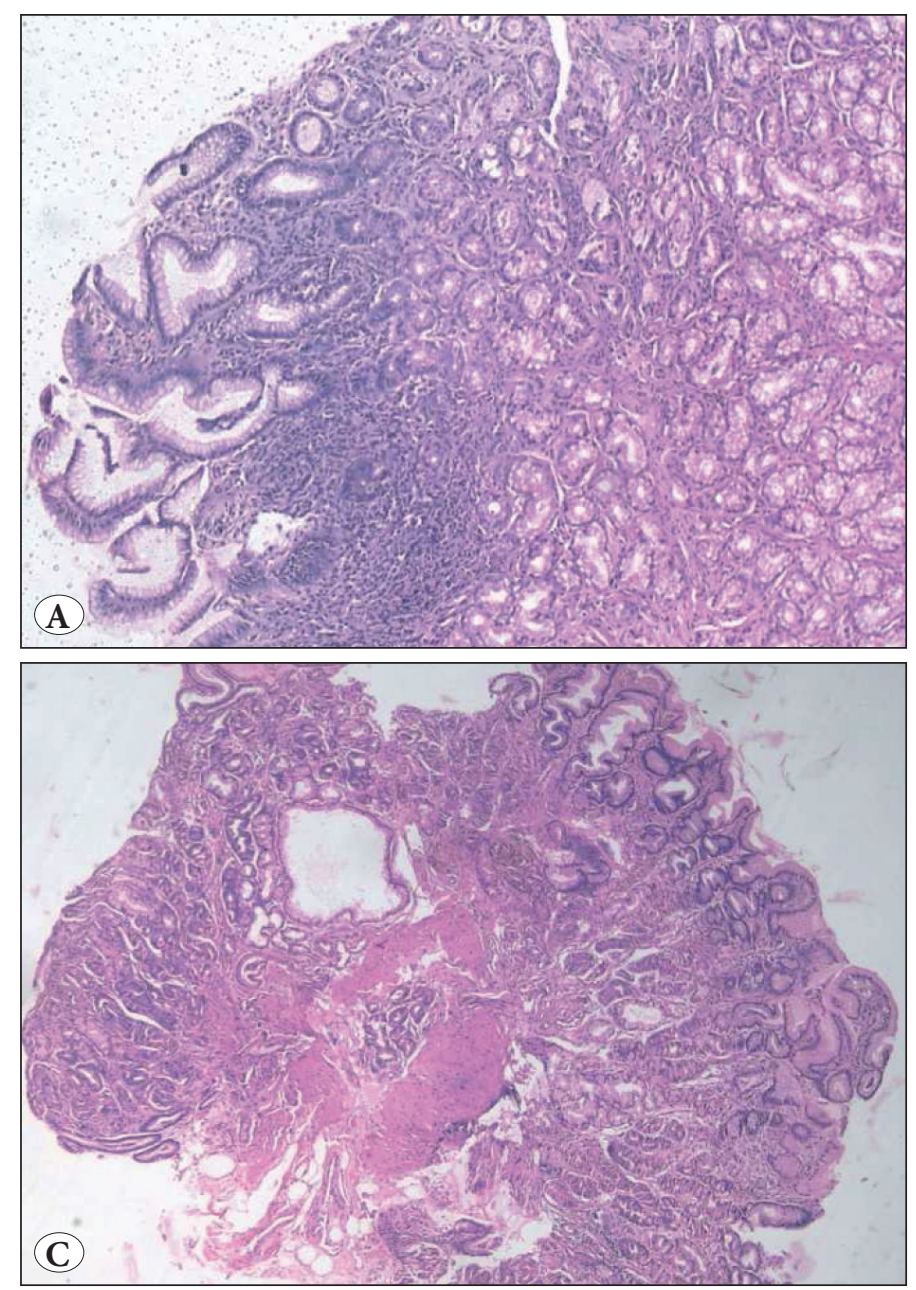

\section{Lungs}

The effect of DMBA and erucin alone and in combination on the lungs of male Wistar rats was also analyzed in the current study. The histological changes in the lungs of rat were categorized in six different parameters with further subtypes. These changes were disease pattern (absent, localized and generalized), intra-alveolar congestion (absent and present), intra-alveolar infiltration by inflammatory cells (mild, moderate and severe), alveolar hyperplasia (absent and present), interstitial inflammation (mild, moderate and severe) and interstitial fibrosis (mild, moderate and severe). The changes were recorded as per the damage observed in the prepared slides. It was seen that the rats treated with DMBA alone showed the highest damage with a score of $9 / 13$. All the damaging characteristics were
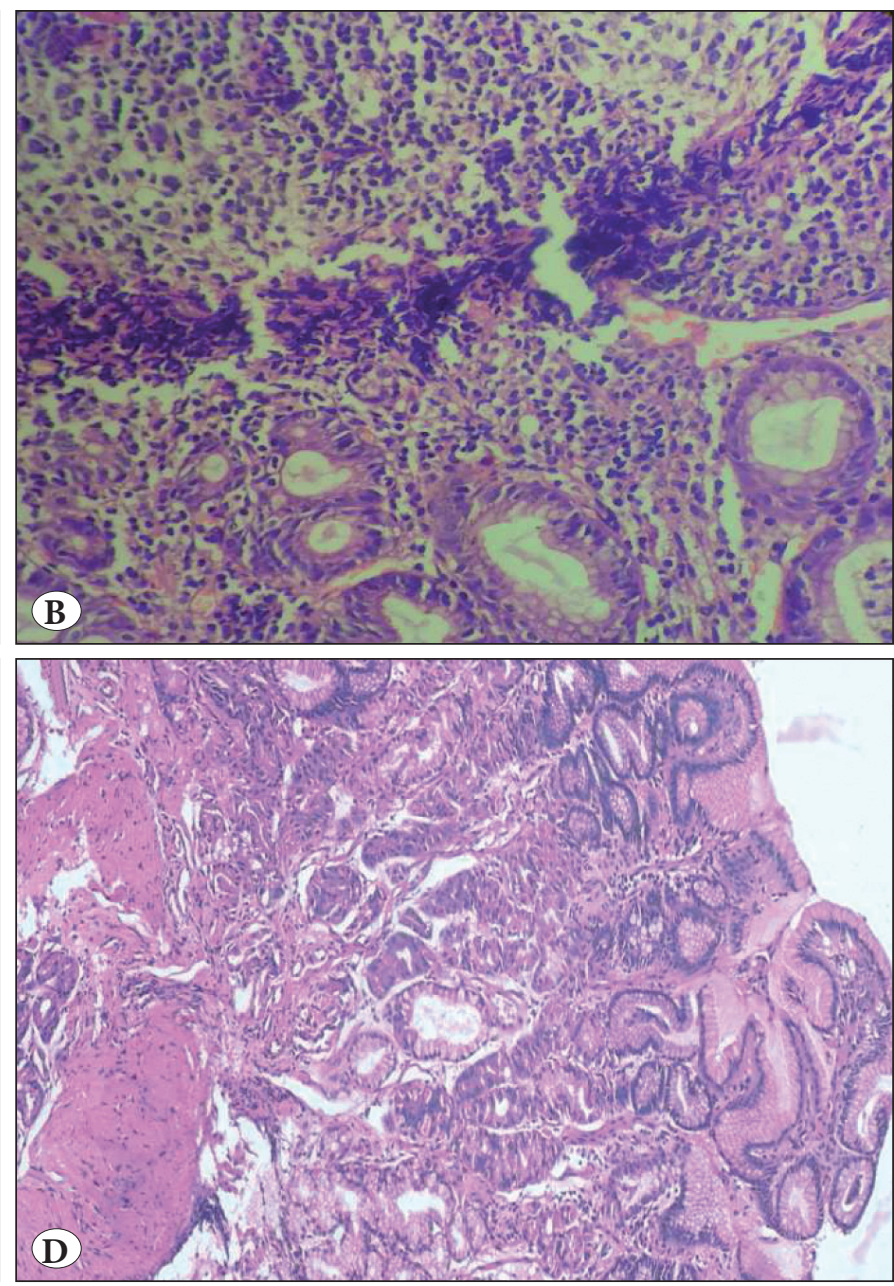

Figure 2: Figure representing gastric histopathology following the treatment with DMBA alone and in combination with erucin. A) Mucosal ulceration with moderate degree of chronic inflammation (H\&E; x400) [DMBA + erucin (50 mg/kg bw)]. B) Neutrophilic infiltrate in the biopsy showing evidence of moderate activity (H\&E; x1000) [DMBA + erucin (35 mg/kg bw)]. C) Mucosal flattening and moderate degree of gastric atrophy with focal evidence of intestinal metaplasia (H\&E; x200) [DMBA + erucin (20 mg/kg bw)]. D) Intestinal metaplasia (goblet cells) (H\&E; x400) [DMBA alone]. 
Table I: Gastric abnormalities scored using Baylor Modification of "The Sydney System”

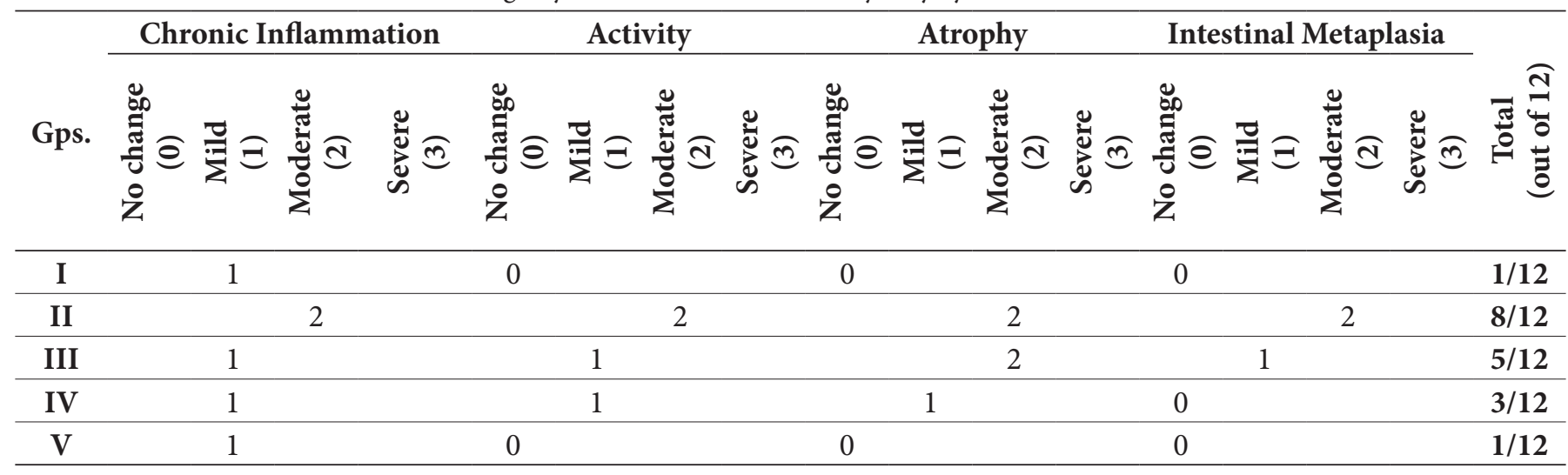

Gps: Groups. Group I: untreated control; Group II: DMBA (20 mg/kg bw); Group III: DMBA + erucin (20 mg/kg bw); Group IV: DMBA + erucin (35 $\mathrm{mg} / \mathrm{kg} \mathrm{bw})$; Group V: DMBA + erucin $(50 \mathrm{mg} / \mathrm{kg}$ bw)

Table II: Method for scoring the damage incurred by lung tissue of the animal

\begin{tabular}{|c|c|c|c|c|c|c|c|c|c|c|c|c|c|c|c|c|c|}
\hline \multirow[b]{2}{*}{ Gps } & \multicolumn{3}{|c|}{ Disease Pattern } & \multicolumn{2}{|c|}{$\begin{array}{c}\text { Intra-Alveolar } \\
\text { Congestion }\end{array}$} & \multicolumn{3}{|c|}{$\begin{array}{l}\text { Intra-Alveolar } \\
\text { Infiltration }\end{array}$} & \multicolumn{2}{|c|}{$\begin{array}{c}\text { Alveolar } \\
\text { Hyperplasia }\end{array}$} & \multicolumn{3}{|c|}{$\begin{array}{c}\text { Interstitial } \\
\text { Inflammation }\end{array}$} & \multicolumn{3}{|c|}{$\begin{array}{c}\text { Interstitial } \\
\text { Fibrosis }\end{array}$} & \multirow[b]{2}{*}{$\frac{\widehat{m}}{\stackrel{\tilde{m}}{0}}$} \\
\hline & $\begin{array}{l}\overrightarrow{0} \\
0 \\
0\end{array}$ & 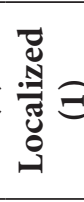 & 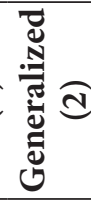 & 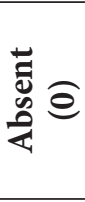 & 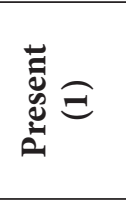 & 흘 & 茪 & i⿱⿱亠凶禸心 & 莒 & 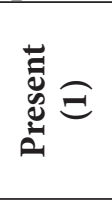 & $\bar{z}$ & 营 & 离 & $\sqrt{2} \bar{z}$ & 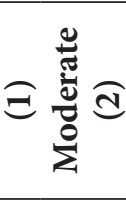 & 离 $\widehat{\infty}$ & \\
\hline I & 0 & 1 & 0 & 0 & 0 & 0 & 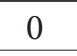 & 0 & 0 & 0 & 1 & 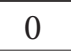 & 0 & 1 & 0 & 0 & $3 / 13$ \\
\hline II & 0 & 0 & 2 & 0 & 1 & 1 & 0 & 0 & 0 & 1 & 0 & 2 & 0 & 0 & 2 & 0 & $9 / 13$ \\
\hline III & 0 & 1 & 0 & 0 & 0 & 1 & 0 & 0 & 0 & 0 & 0 & 2 & 0 & 1 & 0 & 0 & $5 / 13$ \\
\hline IV & 0 & 1 & 0 & 0 & 0 & 0 & 0 & 0 & 0 & 0 & 0 & 2 & 0 & 1 & 0 & 0 & $4 / 13$ \\
\hline V & 0 & 1 & 0 & 0 & 0 & 0 & 0 & 0 & 0 & 0 & 1 & 0 & 0 & 1 & 0 & 0 & $3 / 13$ \\
\hline
\end{tabular}

Gps: Groups. Group I: untreated control; Group II: DMBA (20 mg/kg bw); Group III: DMBA + erucin (20 mg/kg bw); Group IV: DMBA + erucin (35 $\mathrm{mg} / \mathrm{kg} \mathrm{bw})$; Group V: DMBA + erucin (50 mg/kg bw)s

observed in the tissue, suggesting severe microstructural changes in this group. In contrast, a low damage of $3 / 13$ was observed in the untreated control. The slight damage observed in this group might be due to the continuous delivery of corn oil to the intraperitoneal cavity of the animal. As seen in the stomach, a dose-dependent result was observed in the lungs of rats treated with DMBA in addition to erucin $(20,35$ and $50 \mathrm{mg} / \mathrm{kg} \mathrm{bw})$. The erucin treatment ameliorated the damage incurred on the lungs as seen by a reduction in damage score to $5 / 13,4 / 13$ and $3 / 13$ in the low, medium and high erucin treated group (Table II, Figure 3A-F).

\section{DISCUSSION}

Increasing pollution and drastic change in the lifestyle these days have made us susceptible to various deleterious effects (10). These pollutants are also responsible for inducing various microstructural changes in the vital organs of the body (11). The xenobiotic compounds are metabolized by liver but other organs such as the lungs, stomach and kidneys play a key role in their metabolism and excretion (12-14). These xenobiotic compounds are countered efficiently by plant secondary metabolites such as isothiocyanates (15). Among the various isothiocyanates, erucin (an analogue of sulforaphane) has been isolated and evaluated for its ability to protect the rats against the toxic effect of DMBA. The current study was therefore designed to investigate the role of erucin against the deleterious effect of the pollutant DMBA on the lungs, stomach and kidneys of male Wistar rats. The mutagen and test compound were unable to induce any histopathological changes in the kidney of the rats suggesting that DMBA is completely metabolized by liver and other organs and thus it has no negative effect on kidneys. In addition, the test compound erucin had no toxicity as observed by an absence of microstructural changes. 

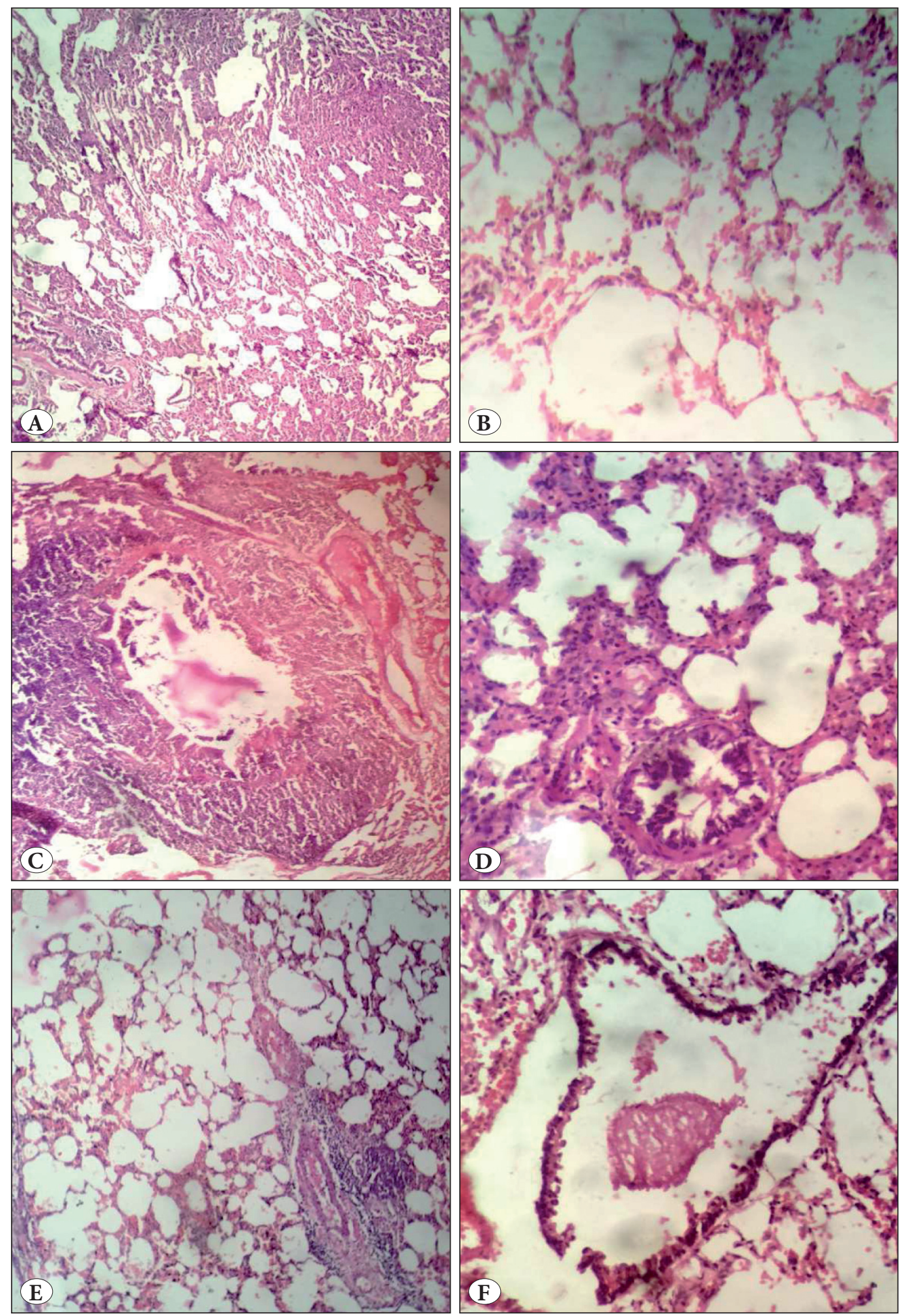

Figure 3: Figure representing lung histopathology following the treatment with DMBA alone and in combination with erucin.

A) Generalised inflammatory response in lung parenchyma $(\mathrm{H} \& \mathrm{E} ; \mathrm{x} 400)[\mathrm{DMBA}+$ erucin $(50 \mathrm{mg} / \mathrm{kg} \mathrm{bw})]$. B) Mild intra-alveolar congestion (H\&E; x1000) $[\mathrm{DMBA}+\operatorname{erucin}(35 \mathrm{mg} / \mathrm{kg}$ bw)].

C) Dense inflammatory infiltrate and interstitial fibrosis around the terminal bronchiole in lung parenchyma (H\&E; x1000) $[\mathrm{DMBA}+\operatorname{erucin}(20 \mathrm{mg} / \mathrm{kg}$ bw)]. D) Alveolar hyperplasia in lung parenchyma $(\mathrm{H} \& \mathrm{E}$; $\mathrm{x} 1000)$ [DMBA alone]. E) Mild to moderate interstitial inflammation in lung parenchyma $(\mathrm{H} \& \mathrm{E}$; x1000)[DMBA alone]. F) Interstitial fibrosis in lung parenchyma (H\&E; x1000) [DMBA alone].

Since the mutagen (DMBA) was administered in the intraperitoneal cavity, it increased the susceptibility of the stomach to its toxicity. This was confirmed by marked microstructural changes in the tissue of experimental animals. DMBA acts as a genotoxic mutagen and causes the formation of DNA adducts (16). These adducts alter the genetic makeup of the rats and thus cause a number of changes in the physiological and physical makeup 
of stomach. Among the different changes, chronic inflammation was observed in the stomach lining of rats. This inflammation is caused by the action of drug on the lining of stomach and a prolonged contact results in further degradation (17). A study by Coussens and Werb has proved a link between inflammation and onset of cancer (18). The DMBA administration was also responsible for further degradation of the stomach as observed by increased atrophy. The activity of stomach is also reduced by the action of DMBA. This reduced activity develops due to lower enzyme function, altered by the action of drug. The combined damaging effects of DMBA in the stomach caused by the transformation of gastric epithelium. This intestinal metaplasia further degraded the normal functioning of rat tissue. In contrast, the treatment with erucin was able to counter the deleterious role of DMBA and helped in protecting the stomach microstructural makeup of male Wistar rats. A thorough literature survey has shown the bioprotective role of isothiocyanates (ITCs) $(19,20)$. These metabolites protect the various organs of an organism viz. lungs, liver and stomach against different carcinogens. They are known to inhibit DNA adduct formation and counter phase I and phase II xenobiotic enzymes $(3,21)$.

The administration of DMBA induced a generalized disease pattern in the lungs of rats. Intra-alveolar congestion and infiltration were seen in tissues of the animal. The alveoli were readily swollen and filled with blood due to the prolonged action of DMBA. This alveolar swelling caused increased opacity and density of the tissue, hampering the normal functioning of the lungs of rats. The volatile nature of this compound further caused an increased irritation in the tissue and thus increased damage (22). The combined effect of the above damage is responsible for atypical alveolar hyperplasia. The size of organ was enlarged due to the activity of DMBA. The mutagen causes the formation of DNA adducts and thus elevated inflammation and thickening or scarring of the pulmonary tissue. The treatment with erucin on the other hand prevented the formation of DNA adducts and protected the lungs of rats from the deleterious effects of DMBA. A study by Hecht et al. has shown the bioprotective role of ITCs against polyaromatic hydrocarbons-induced toxicity in A/J mouse (23). The ability of isothiocyanates to ameliorate the carcinogen metabolism has been shown in a number of different studies $(24,25)$.

In conclusion, the current study was designed to investigate the bioprotective role of erucin against DMBA-induced microstructural changes in male Wistar rats. It was observed that DMBA caused severe changes in the physical makeup of lungs and stomach of the animal. The test compound erucin, on the other hand, protected the animal against these severe changes and is thus a suitable candidate for further studies. No alteration was observed in kidneys of the animals following the treatment with DMBA, erucin or their combination.

\section{ACKNOWLEDGEMENT}

The authors would like to acknowledge the financial assistance by Department of Science and Technology (DST), New Delhi and University with Potential for Excellence (UPE) scheme of University Grants Commission (UGC), New Delhi.

\section{CONFLICT of INTEREST}

The authors pose no conflict of interest.

\section{REFERENCES}

1. Bouchereau A, Aziz A, Larher F,Martin-Tanguy J. Polyamines and environmental challenges: Recent development. Plant Sci. 1999;140:103-25.

2. Morris JJ, Seifter E. The role of aromatic hydrocarbons in the genesis of breast cancer. Med hypotheses. 1992;38:177-84.

3. Arora R, Bhushan S, Kumar R, Mannan R, Kaur P, Singh AP, Singh B, Vig AP, Sharma D, Arora S. Hepatic dysfunction induced by 7, 12-dimethylbenz ( $\alpha$ ) anthracene and its obviation with erucin using enzymatic and histological changes as indicators. PloS one. 2014;9:e112614.

4. Rates SMK. Plants as source of drugs. Toxicon. 2001;39:603-13.

5. Verma S, Singh SP. Current and future status of herbal medicines. Vet World. 2008;1:347-50.

6. Vig AP, Rampal G, Thind TS, Arora S. Bio-protective effects of glucosinolates-A review. LWT-Food Sci Technol. 2009;42:156172 .

7. Chauhan N, Singh D, Painuli RM. Screening of bioprotective properties and phytochemical analysis of various extracts of Eclipta alba whole plant. Int J Pharm Pharm Sci. 2012;4:554-60.

8. Arora R, Vig AP, Arora S. Glucosinolates: Transposing trends of identification methods from paper chromatography to microchip analysis. Int J Life Sci Biotechnol Pharm Res.2014;3:42-61.

9. Arora R, Singh B, Vig AP, Arora S. Conventional and modified hydrodistillation method for the extraction of glucosinolate hydrolytic products: A comparative account. SpringerPlus. 2016;5:1-4.

10. Stefani GP, Baldissera G, Nunes RB, Heck TG, Rhoden CR. Metabolic syndrome and DNA damage: The interplay of environmental and lifestyle factors in the development of metabolic dysfunction. Open J Endocr Metab Dis. 2015;5:65-76.

11. Ezzi L, Salah IB, Haouas Z, Sakly A, Grissa I, Chakroun S, Kerkeni E, Hassine M, Mehdi M, Cheikh HB. Histopathological and genotoxic effects of chlorpyrifos in rats. Environ Sci Pollut Res. 2016;23:4859-67. 
12. Hanninen O, Lindstrom-Seppa P, Pelkonen K. Role of gut in xenobiotic metabolism. Arch Toxicol. 1987;60:34-6.

13. Courcot E, Leclerc J, Lafitte JJ, Mensier E, Jaillard S, Gosset P, Shirali P, Pottier N, Broly F, Lo-Guidice JM. Xenobiotic metabolism and disposition in human lung cell models: Comparison with in vivo expression profiles. Drug Metab Dispos. 2012;40:1953-65.

14. Knights KM, Rowland A, Miners JO. Renal drug metabolism in humans: The potential for drug-endobiotic interactions involving cytochrome P450 (CYP) and UDP-glucuronosyltransferase (UGT). Br J Clin Pharmacol. 2013;76:587-602.

15. Kumar R, Kaur R, Singh AP, Arora S. Diminution of hepatic response to 7, 12-dimethylbenz ( $\alpha$ ) anthracene by ethyl acetate fraction of Acacia catechu willd. through modulation of xenobiotic and anti-oxidative enzymes in rats. PloS one. 2014;9:e90083.

16. Maayah ZH, Ghebeh H, Alhaider AA, El-Kadi AO, Soshilov AA, Denison MS, Ansari MA, Korashy HM. Metformin inhibits 7, 12-dimethylbenz [a] anthracene-induced breast carcinogenesis and adduct formation in human breast cells by inhibiting the cytochrome P4501A1/aryl hydrocarbon receptor signaling pathway. Toxicol Appl Pharmacol. 2015;284:217-26.

17. Tabuchi Y, Ogino T, Mitsuno T, Sugiyama T. Possible role of mucosal damage in stomach carcinogenesis with $\mathrm{N}$-methyl$\mathrm{N}$ '-nitro-N-nitrosoguanidine in the rat. J Natl Cancer Inst. 1974;52:1589-94.
18. Coussens LM, Werb Z. Inflammation and cancer. Nature.2002;420:860-7.

19. Zhang Y, Talalay P. Anticarcinogenic activities of organic isothiocyanates: Chemistry and mechanisms. Cancer Res. 1994;54:1976s-81s.

20. van Poppel G, Verhoeven DT, Verhagen H, Goldbohm RA. Brassica vegetables and cancer prevention. Epidemiology and mechanisms. Adv Exp Med Biol. 1999;472:159-68.

21. Ramos-Gomez M, Dolan PM, Itoh K, Yamamoto M, Kensler TW. Interactive effects of nrf2 genotype and oltipraz on benzo [a] pyrene-DNA adducts and tumor yield in mice. Carcinogenesis. 2003;24:461-7.

22. Gminski R, Tang T, Mersch-Sundermann V. Cytotoxicity and genotoxicity in human lung epithelial A549 cells caused by airborne volatile organic compounds emitted from pine wood and oriented strand boards. Toxicol Lett. 2010;196:33-41.

23. Hecht SS, Kenney PM, Wang M, Upadhyaya P. Benzyl isothiocyanate: An effective inhibitor of polycyclic aromatic hydrocarbon tumorigenesis in A/J mouse lung. Cancer Lett. 2002;187:87-94.

24. Talalay P, Fahey JW. Phytochemicals from cruciferous plants protect against cancer by modulating carcinogen metabolism. J Nutr. 2001;131:3027S-33S

25. Balansky R, Ganchev G, Iltcheva M, Steele VE, De Flora S. Prevention of cigarette smoke-induced lung tumors in mice by budesonide, phenethyl isothiocyanate, and $\mathrm{N}$-acetylcysteine. Int J Cancer. 2010;126:1047-54. 